\title{
The cross-currency hedging performance of implied versus statistical forecasting models
}

Article

Accepted Version

Brooks, C. and Chong, J. (2001) The cross-currency hedging performance of implied versus statistical forecasting models. Journal of Futures Markets, 21 (11). pp. 1043-1069. ISSN 1096-9934 doi: https://doi.org/10.1002/fut.2104 Available at https://centaur.reading.ac.uk/35960/

It is advisable to refer to the publisher's version if you intend to cite from the work. See Guidance on citing.

Published version at: http://dx.doi.org/10.1002/fut.2104

To link to this article DOI: http://dx.doi.org/10.1002/fut.2104

Publisher: Wiley

All outputs in CentAUR are protected by Intellectual Property Rights law, including copyright law. Copyright and IPR is retained by the creators or other copyright holders. Terms and conditions for use of this material are defined in the End User Agreement.

www.reading.ac.uk/centaur

\section{CentAUR}


Central Archive at the University of Reading

Reading's research outputs online 
This is the authors' accepted manuscript of an article published in the Journal of Futures Markets. The definitive version is available at www3.interscience.wiley.com 


\title{
The Cross-Currency Hedging Performance of Implied Versus Statistical Forecasting Models
}

\author{
CHRIS BROOKS, ISMA Centre, University of Reading" \\ JAMES CHONG, ISMA Centre, University of Reading
}

\begin{abstract}
This paper examines the ability of several models to generate optimal hedge ratios. Statistical models employed include univariate and multivariate GARCH models, and exponentially weighted and simple moving averages. The variances of the hedged portfolios derived using these hedge ratios are compared with those based on market expectations implied by the prices of traded options. One-month and three-month hedging horizons are considered for four currency pairs. Overall, we find that an exponentially weighted moving average model leads to lower portfolio variances than any of the GARCH-based, implied or time-invariant approaches.
\end{abstract}

\section{DECEMBER 2000}

\footnotetext{
- Author for correspondence. Chris Brooks, ISMA Centre, Department of Economics, University of Reading, Whiteknights, PO Box 242, Reading RG6 6BA, UK. Tel: +44 11893167 68; Fax: +44 11893147 41; Email: C.Brooks@reading.ac.uk. The authors are grateful to two anonymous referees for useful comments on a previous version of this paper. The usual disclaimer applies.
} 


\section{INTRODUCTION}

The issue of volatility forecasting has witnessed immense interest from academics in the past decade. Though closely related to volatility forecasting, the variety of models employed for the prediction of hedging ratios has been limited. Hedging is an attempt to reduce the risk of an exposure to movements of an asset by taking an offsetting position in another asset. For example, in the context of foreign exchange risk, a global fund management firm will probably desire to hedge such exposures. The firm's purpose is presumably to maximize profits from the stock market and it will therefore not want its performance to be affected by the movement of currencies. Further, manufacturing firms who export or import raw materials will also want to minimize their exposure to exchange rate movements. Hence, it is of utmost importance that fund management and other firms employ the most effective models in determining the optimal hedge ratio, rather than simply relying on a conventional model.

Early literature in this area tended to focus on estimating hedge ratios via an ordinary least squares (OLS) regression of the spot price on the futures price (Ederington, 1979; Anderson and Danthine, 1980), the slope coefficient obtained being the hedge ratio. However, such an approach does not take into account the time varying nature of covariances and variances which make up the hedge ratio. That the variances of asset returns are time-varying has since been recognized with the advent of the autoregressive conditionally heteroscedastic (ARCH) model of Engle (1982) and the generalized ARCH (GARCH) model of Bollerslev (1986). Recent literature has dealt mostly with estimating hedge ratios by employing bivariate GARCH models, in the form of the constant correlation model (Bollerslev, 1990) or the VECH model (Bollerslev, Engle, and Wooldridge, 1988). The various financial instruments covered in the literature on hedging that employs such a methodology, include commodity 
futures (Baillie and Myers, 1991; Garcia, Roh and Leuthold, 1995; Bera, Garcia and Roh, 1997), currency futures (Kroner and Sultan, 1991, 1993; Lin, Najand and Yung, 1994), interest rate futures (Gagnon and Lypny, 1995), and stock index futures (Park and Switzer, 1995; Tong, 1996).

It is also possible that, instead of hedging currency risk using futures, a firm may wish to hedge its exposure to one currency by forming an opposite position in another. Such an approach is employed by Siegel (1997). Employing currency and cross-currency options on the Philadelphia Stock Exchange (PHLX), Siegel assesses the performances of the regression-based model and the implied correlation by their beta hedge ratio. The beta hedge ratio is the ratio for hedging the risk (denominated in USD) of holding one currency by selling an offsetting amount of another currency. The options examined are for the currencies USD/DEM, USD/JPY, DEM/JPY, GBP/USD, and GBP/DEM. The two tests performed on the beta hedge ratio are 1) to assess the volatility of the hedged position, and 2) multiple regression analysis to ascertain the incremental information content of each hedge ratio. In both tests, the author finds that the implied beta hedge ratio performs better than the regression-based beta hedge ratio.

This paper attempts to provide a comprehensive review of various implied and statistical hedging models by employing over-the-counter currency options data. As such, this study follows in spirit, and considerably extends, that conducted by Siegel (1997). This paper reviews a wider variety of empirically relevant models and employs a longer data set. Siegel compares only historical and implied measures, while this paper also evaluates the performance of various conditional variance and covariance estimators found to be more useful than historical measures in other studies. Although hedging currency risk with 
currency futures would be more effective in many cases, often firms will obtain a "natural hedge" where they have opposite exposures to movements in two or more currencies. This would occur where a firm has effectively a long position in one foreign currency and a short position in another. Take, for example, the case of a US multinational corporation that exports to Germany and imports from Japan, then there is a natural hedge that is often overlooked. Jorion (2000, p.475) argues that until recently, hedging systems typically consisted of focusing on and hedging each source of risk separately. An example would be for multinational corporations to evaluate their transaction risks in various currencies and to hedge them individually. This is an inefficient approach as it ignores the correlations that exist among the various exchange rate movements. One way to counter currency risks and to save on transaction costs is to first take advantage of the natural hedge and then to reduce the residual risk via futures contracts. Thus, even though futures provide a more effective hedging instrument than cross-currency positions, the latter will still be of importance to any firms with partially off-setting international exposures ${ }^{1}$. Survey evidence ${ }^{2}$ indicates that only $50 \%$ of US non-financial firms use derivatives to hedge, although foreign exchange risks were more commonly managed with derivatives than any other forms of risk. $60 \%$ of firms were found to balance out total foreign currency revenues with foreign currency expenses, giving further motivation for our study.

To anticipate our main findings, we observe that while no single model is uniformly superior across all currency pairs and hedging horizons, neither the implied nor the simple historical models perform particularly well. In the remaining sections of this paper, the data set and

\footnotetext{
${ }^{1}$ Our findings show that the cross-currency hedge can reduce volatility by around $15 \%$. A separate analysis using futures contracts (not shown, but available from the authors on request), showed that risk reduction in this case would be of the order of $60 \%-80 \%$ depending on the currency pairs.

2 "Survey of Derivatives Usage by US Non-financial Firms", conducted by the Weiss Centre for International Financial Research, Wharton School and CIBC World Markets, 1998.
} 
methodology are described, followed by the test results comparing the hedging capabilities of the various models. The study ends with the summary and conclusion.

\section{DATA}

The data employed for this study are on spot currencies and currency options and are provided by a prominent bank based in London dealing in these instruments, collected at 16:00 GMT. This reduces the errors resulting from non-synchronous prices. The data spans the period 19 July 1993 to 13 September 1999, a length of time slightly more than six years and a total of 1,605 daily observations. The options data consists of over-the-counter (OTC) price quotes for USD/DEM (interpreted as DEM per USD), USD/JPY, DEM/JPY, GBP/USD and GBP/DEM. These currency options are traded inter-bank and the price quotes refer to an at-the-money forward straddle, a combination of one European call option and one European put option at the same exercise price equaling the forward rate. Times-to-expiration are onemonth and three-months. The norm for such options is a quotation in terms of implied volatility (percent per year), which could be derived from the Garman-Kohlhagen option pricing model (Garman and Kohlhagen, 1983). This model is the foreign exchange equivalent to the model of Black and Scholes (1973).

\section{OTC and Exchange Traded Options}

The implied volatility data could also be derived from currency options listed on exchanges such as the PHLX. However, there are a few differences that tend to favor using OTC data. The first difference is that the OTC currency options market is more liquid than the PHLX. In the Bank of International Settlements 'Central Bank Survey of Foreign Exchange and Derivatives Market Activity 1995' (1996), both outstanding notional amounts and average daily turnover (adjusted for local and cross-border double counting) for OTC and exchange- 
traded currency options were reported. At end-March 1995, the outstanding notional amounts for the OTC USD/DEM, USD/JPY and DEM/JPY options were USD518.720 billion, USD625.163 billion, and USD93.991 billion respectively. The corresponding exchangetraded outstanding notional amounts were USD36.395 billion, USD21.749 billion, and USD230 million respectively. The daily average turnover for the OTC USD/DEM, USD/JPY, DEM/JPY, GBP/USD, and GBP/DEM options were USD10.241 billion, USD13.266 billion, USD1.936 billion, USD1.288 billion, and USD1.366 billion respectively. Corresponding figures on the exchange-traded markets were USD1.233 billion, USD842 million, USD16 million, USD166 million, and USD9 million respectively. ${ }^{3}$ A second difference is in the options' time-to-expiration. For OTC currency options, the time-to-expiration is constant in that there are daily quotes for one- and three-month implied volatility. With exchange-traded currency options, specific expiration dates result in varying time-to-expirations. Hence with OTC currency options, it is not necessary to adjust the implied volatilities for the options' time decay. The third difference is with regard to moneyness. OTC currency options are quoted at-the-money forward, which reduces the 'smile' effects when implied volatility varies with exercise price. With the exercise prices of exchange-traded currency options set at discrete intervals, the implied volatilities computed are at best derived from nearest-themoney options.

\section{Day-Count Convention}

In computing the various hedge ratio forecasts, we employ the modified day count convention consistent with market practice. Using a one-month currency option as an example, the contract settles in one calendar month from the spot value date, which is two

\footnotetext{
${ }^{3}$ The triennial survey was updated in 1998. However, as the reporting framework is limited to OTC markets, it is not possible to obtain comparative figures for OTC and exchange-traded currency options. Outstanding notional amounts are also not available for the currency options examined. Nevertheless, in April 1998, the average daily turnover for the OTC USD/DEM, USD/JPY, DEM/JPY, GBP/USD and GBP/DEM options were
} 
business days from the spot transaction. If the day in which the contract settles is not a business day, the settlement date is brought forward to the next business day. However, should the next business day cross into the next calendar month, then the settlement date will be brought backwards to the previous business day (following Breuer and Wohar, 1996). Hence the time-to-expiration for the one-month currency option in our sample ranges from 23 to 27 trading days. The number of trading days ranges from 66 to 69 for the three-month currency option.

\section{METHODOLOGY}

\section{Calculating the Optimal Hedge Ratio}

The objective of a hedge is to reduce the risk of investing in a currency $X$ (for example, USD/DEM) by holding an offsetting position in another currency $Y$ (for example, USD/JPY) or in a currency futures contract (a USD/DEM futures). To gauge the effectiveness of a hedge, we evaluate the variability of the investor's portfolio and the hedge that results in the largest volatility reduction for the hedged portfolio is considered the most effective ${ }^{4}$. The optimal hedge ratio (OHR), the hedge ratio that minimizes the conditional variance of the hedged portfolio, can be derived (Kroner and Sultan, 1991) as

$$
\beta_{t}=-\frac{\sigma_{t}\left(x_{t+1}, y_{t+1}\right)}{\sigma_{t}^{2}\left(y_{t+1}\right)},
$$

where $\sigma_{t}\left(x_{t+1}, y_{t+1}\right)$ is the covariance at time $t$ between the logarithmic returns of currency $X$ and $Y$, and $\sigma_{t}^{2}\left(y_{t+1}\right)$ is the variance at time $t$ of currency $Y$ logarithmic returns. This ratio is similar to the conventional hedge ratio obtained from ordinary least squares with the exception of the covariance and variances being time varying.

USD17.393 billion, USD33.262 billion, USD5.257 billion, USD3.837 billion, and USD4.998 billion respectively. 


\section{Hedging Models}

The hedging models under study are categorized as naïve, implied, historical (random walk, simple historical, EWMA), univariate GARCH (GARCH, EGARCH, GJR, GARCH- $t$ ), and multivariate GARCH (VECH, BEKK) models. This constitutes a total of eleven models under review. The various models are used to capture different stylized features of the currency returns under consideration.

\section{Nä̈ve Model}

The naïve hedge assumes a hedge ratio of -1 at all times.

\section{Implied Model}

The implied model forecasts the conditional covariance by employing implied volatilities derived from currency options. The implied variance of the cross-currency returns $x y$ is given by

$$
\tilde{\sigma}^{2}(x y)=\tilde{\sigma}^{2}(x)+\tilde{\sigma}^{2}(y)-2 \tilde{\sigma}(x, y),
$$

where $\tilde{\sigma}^{2}(x)$ and $\tilde{\sigma}^{2}(y)$ are the implied variances of the $X$ and $Y$ returns, $x$ and $y$, respectively, and $\tilde{\sigma}(x, y)$ is the implied covariance between $x$ and $y$. By substituting the observed option implied volatilities of the three currencies into (2), the implied covariance is obtained via

$$
\tilde{\sigma}(x, y)=\frac{\tilde{\sigma}^{2}(x)+\tilde{\sigma}^{2}(y)-\tilde{\sigma}^{2}(x y)}{2} .
$$

So, for instance, if the implied hedge ratio for hedging USD/DEM with USD/JPY is of interest, then the implied variances of the returns of USD/DEM and USD/JPY, as well as the

\footnotetext{
${ }^{4}$ The Survey of Derivatives research discussed previously found that $40 \%$ of US non-financial firms view the
} 
returns of the cross-currency DEM/JPY, are required so as to obtain the implied hedge ratio using equation (1).

Since the forecast of the hedging ratio using this model is based on option-derived variances, an implicit shortcoming is that an option pricing model has to be determined first. Even then, one cannot be certain that the model specifications are correct. A further limitation of this approach is the fixed forecast horizon. That is, the implied hedge ratio from a one-month option is only appropriate for a one-month forecast horizon and not for a forecast of any other number of days.

\section{Historical Models}

\section{The Random Walk Model}

The random walk model assumes that the most appropriate forecast of tomorrow's and subsequent days' variance or covariance, is the variance or covariance observed today. This simplest model employs realized covariances and variances $T$ days (which depends on the time to maturity of the option: see the section on day-count conventions) prior to time $t$, that is $\sigma_{t-T}(x, y)$ and $\sigma_{t-T}^{2}(y)$ respectively, to determine the hedge ratio.

\section{The Conventional/Simple Historical Model}

The simple historical hedge ratio is simply the ratio of the equally weighted average of realized covariance and variance. One of the most commonly used hedge ratios is the conventional hedge, where the OHR is computed as the least squares estimator. This is achieved by simply regressing the historical daily return series of the currency to be hedged on those for the hedging instrument (be it a currency or currency futures), multiplied by -1 .

reduction of volatility as the main objective of hedging. 
As shown in Watsham and Parramore (1997, pp.192-194), the conventional hedge is equivalent to the OHR determined by the simple historical model.

\section{The EWMA Model}

RiskMetrics $^{\mathrm{TM}}$ (J.P. Morgan/Reuters, 1996), the popular risk measurement software (based on value at risk), forecasts covariances and variances using an exponentially weighted moving average (EWMA) model. Under an EWMA specification, the latest observation carries the largest weight, and weights associated with previous observations decline exponentially over time. This approach has two advantages over the simple historical and the random walk models. First, volatility is affected more by recent events, which carry more weight, than events in the past. Second, the effect on volatility of a single given observation declines at an exponential rate as weights attached to recent events fall. On the other hand, the simple historical approach could lead to an abrupt change in volatility once the shock falls out of the measurement sample. And if the shock is still included in a relatively long measurement sample period, then an abnormally large observation will imply that the forecast will remain at an artificially high level even if the market is subsequently tranquil. The one-day EWMA covariance and variance forecast is represented by

$$
\begin{aligned}
& \sigma(x, y)_{t+1 \mid t}=(1-\lambda) \sum_{i=0}^{\infty} \lambda^{i} x_{t-i} y_{t-i}, \\
& \sigma^{2}(y)_{t+1 \mid t}=(1-\lambda) \sum_{i=0}^{\infty} \lambda^{i} y_{t-i}^{2} .
\end{aligned}
$$

$\lambda(0<\lambda<1)$ is referred to as the decay factor and determines the relative weights attached to the observations. In the RiskMetrics ${ }^{\mathrm{TM}}$ technical document, it is suggested that for one-day forecasts, $\lambda$ should be 0.94 , and this approach is also followed here. 


\section{The GARCH Family of Models}

The autoregressive conditional heteroscedasticity $(\mathrm{ARCH})$ family of models is a group of models that mimics changing variances witnessed in the volatility clustering of asset returns. Volatility clustering occurs when "large changes tend to be followed by large changes, of either sign, and small changes tend to be followed by small changes" (Mandelbrot, 1963, p.418). GARCH models (when extended as necessary) have also been able to capture other behavior of financial time series such as thick tails, leverage effects, serial correlation in volatility, and co-movements in volatilities.

To forecast the conditional covariance using univariate GARCH models, individual variances of currency returns would have to be modeled and then the conditional covariance would be derived from

$$
\sigma_{t}(x, y)=\frac{h_{t}(x)+h_{t}(y)-h_{t}(x y)}{2}
$$

where the $h$ 's are variances forecast by the various GARCH models. Each of the variants from the GARCH family employed in this paper are now described.

\section{The GARCH(1,1) Model}

As mentioned above, rates of return are characterized by tranquil and volatile periods. To allow for such dependence, suppose the conditional mean to be

$$
x_{t}=\mu+\varepsilon_{t},
$$

where, $\varepsilon_{t}=z_{t} \sqrt{h_{t}}, z_{t} \sim N I D(0,1)$. The conditional variance could then be modeled by the GARCH (1,1) model (Bollerslev, 1986), which is represented by

$$
h_{t}=\gamma+\alpha \varepsilon_{t-1}^{2}+\beta h_{t-1} \text {, }
$$




\section{Asymmetric GARCH Models}

Although the GARCH model captures thick tailed returns and volatility clustering, it is unable to account for any asymmetric response of volatility to positive and negative shocks since the conditional variance in equation (7) is a function of the magnitudes of the lagged residuals and not their signs. However, it has been argued that a negative shock to financial time series is likely to cause volatility to rise by more than a positive shock of the same magnitude. In the case of equity returns, such asymmetries are typically attributed to leverage effects, whereby a fall in the value of a firm's stock causes the firm's debt to equity ratio to rise. This leads shareholders, who bear the residual risk of the firm, to perceive their future cashflow stream as being relatively more risky. Although asymmetries in currency returns cannot be attributed to changing leverage, there is equally no reason to suppose that such asymmetries do not exist. In fact, an application of the Engle and $\mathrm{Ng}$ (1993) size and sign bias tests (not shown due to space constraints but available from the authors upon request) showed evidence of asymmetries in the data analyzed here. Two popular asymmetric formulations are employed in this paper: the exponential GARCH (EGARCH) model proposed by Nelson (1991), and the GJR model, named after the authors Glosten, Jaganathan and Runkle (1993).

The EGARCH(1,1) Model

In the EGARCH(1,1) model, the natural logarithm of the conditional variance follows the process

$$
\ln h_{t}=\gamma+\beta \ln h_{t-1}+\alpha z_{t-1}+\varphi\left(\left|z_{t-1}\right|-\sqrt{2 / \pi}\right),
$$

where $\gamma, \alpha, \beta$, and $\varphi$ are parameters. The motivations for the preference of the $\operatorname{EGARCH}(1,1)$ model over the $\operatorname{GARCH}(1,1)$ are that the latter model cannot explain the asymmetric behavior of the conditional variance in asset price returns, and for the conditional 
variance of the GARCH model to be positive, its parameters have to be positive, which is not required in the EGARCH model. This implies that artificial non-negativity constraints may have to be applied to the former, but are not necessary for the latter.

\section{The GJR(1,1) Model}

The GJR model (Glosten, Jaganathan and Runkle, 1993) is effectively a GARCH formulation that also includes an additional term that captures asymmetry. The GJR(1,1) model is represented by

$$
h_{t}=\gamma+\alpha \varepsilon_{t-1}^{2}+\omega \varepsilon_{t-1}^{2} S_{t-1}^{-}+\beta h_{t-1}
$$

where $\gamma, \alpha, \beta$, and $\omega$ are parameters, and $S_{t-1}^{-}$is an indicator function that takes the value of one when $\varepsilon_{t-1}<0$ and zero otherwise. To ensure an everywhere positive conditional variance, it is sufficient that $\gamma>0, \beta \geq 0$, and $\alpha+\omega \geq 0$. For the process $\varepsilon_{t}$ to be stationary, it is sufficient that $\alpha+\beta+\omega<1$. In the GJR model, the conditional variance follows one process when the innovations are positive and another process when the innovations are negative.

The coefficients of the $\operatorname{GARCH}(1,1), \operatorname{EGARCH}(1,1)$ and $\operatorname{GJR}(1,1)$ models are estimated by the maximum likelihood procedure using the algorithm of Broyden, Fletcher, Goldfarb, and Shanno (BFGS; Broyden, 1965, 1967, and Fletcher and Powell, 1963). Since $z_{t} \sim$ NID $(0,1)$, then the conditional distribution of $x_{t}$ is normal:

$$
f\left(x_{t} \mid \psi_{t-1}\right)=\frac{1}{\sqrt{2 \pi h_{t}}} \exp \left(\frac{-\left(x_{t}-\mu\right)^{2}}{2 h_{t}}\right) .
$$


The sample log likelihood function is then

$$
L(\vartheta)=-\frac{T}{2} \ln (2 \pi)-\frac{1}{2} \sum_{t=1}^{T} \ln \left(h_{t}\right)-\frac{1}{2} \sum_{t=1}^{T} \frac{\left(x_{t}-\mu\right)^{2}}{h_{t}},
$$

where $\vartheta$ denotes the model parameters to be estimated.

\section{The $\operatorname{GARCH}(1,1)-t$ Model}

The GARCH(1,1)- $t$ model (Bollerslev, 1987) was developed with a "fat-tailed" conditional distribution, which might be superior to the conditional normal of the $\operatorname{GARCH}(1,1)$ model. Even though the unconditional distribution of the $\operatorname{GARCH}(1,1)$ with conditionally normal errors is leptokurtic, it is unclear whether the model sufficiently accounts for the observed leptokurtosis in financial time series.

The likelihood function formulation in equation (11) assumes that $z_{t}$ has a normal distribution. Bollerslev proposed that $z_{t}$ be drawn from a $t$ distribution with $v$ degrees of freedom, where $v$ is also a parameter to be estimated by maximum likelihood. The density function of $\varepsilon_{t}$ is given by

$$
f\left(\varepsilon_{t}\right)=\frac{\Gamma[(v+1) / 2]}{\pi^{1 / 2} \Gamma(v / 2)}\left[(v-2) h_{t}\right]^{-1 / 2}\left[1+\frac{\left(x_{t}-\mu\right)^{2}}{h_{t}(v-2)}\right]^{-(v+1) / 2},
$$

where $\Gamma($.$) denotes the gamma function. This density can be used in place of the Gaussian$ specification (10). The log likelihood function (11) will now be

$$
\begin{aligned}
L(\vartheta)= & T \ln \left\{\frac{\Gamma[(v+1) / 2]}{\pi^{1 / 2} \Gamma(v / 2)}(v-2)^{-1 / 2}\right\}-\frac{1}{2} \sum_{t=1}^{T} \ln \left(h_{t}\right) \\
& -\frac{(v+1)}{2} \sum_{t=1}^{T} \ln \left[1+\frac{\left(x_{t}-\mu\right)^{2}}{h_{t}(v-2)}\right]
\end{aligned}
$$

subject to the constraint $v>2$. 


\section{The VECH Model}

The VECH model is very similar to the univariate $\operatorname{GARCH}(1,1)$ model except that its covariance also evolves over time. A common specification of the VECH model is

$$
\begin{gathered}
\operatorname{vech}\left(H_{t}\right)=C+A \operatorname{vech}\left(H_{t-1}\right)+B \operatorname{vech}\left(\Xi_{t-1} \Xi_{t-1}^{\prime}\right) \\
\Xi_{t} \mid \psi_{t-1} \sim N\left(0, H_{t}\right),
\end{gathered}
$$

where $H_{t}$ is a $2 \times 2$ variance-covariance matrix, $\Xi_{t}$ is a $2 \times 1$ innovation vector, $\psi_{t-1}$ represents the information set at time $t-1, C$ is a $3 \times 1$ parameter vector, $A$ and $B$ are $3 \times 3$ parameter matrices and vech(.) denotes the column-stacking operator applied to the lower portion of the symmetric matrix. Given the model's 21 parameters ( $C$ has 3 elements, $A$ and $B$ each have 9 elements), maximization of the log likelihood function is cumbersome. Hence the VECH model's conditional variance-covariance matrix has been restricted to the form developed by Bollerslev, Engle and Wooldridge (1988) in which $A$ and $B$ are assumed to be diagonal. This reduces the number of parameters to be estimated to 9 (now $A$ and $B$ each have 3 elements) and the model, known as a diagonal VECH, is now characterized by

$$
h_{i j, t}=\omega_{i j}+\alpha_{i j} h_{i j, t-1}+\beta_{i j} \varepsilon_{i, t-1} \varepsilon_{j, t-1} \quad \text { for } i, j=1,2
$$

where $\omega_{i j}, \alpha_{i j}$ and $\beta_{i j}$ are parameters. It estimates covariance as a geometrically declining weighted average of past cross products of unexpected returns, with recent observations carrying higher weights. A disadvantage of the VECH model is that there is no guarantee of a positive definite covariance matrix.

\section{The BEKK Model}

The BEKK model (Engle and Kroner, 1995) addresses and solves the issue of positive definiteness. It is represented by 


$$
H_{t}=W+A^{\prime} H_{t-1} A+B^{\prime} \Xi_{t-1} \Xi_{t-1}^{\prime} B
$$

where $W, A, B$ are $3 \times 3$ matrices, with $W$ being symmetric and positive definite. The positive definiteness of the covariance matrix is ensured due to the quadratic nature of the second and third terms on the equation's right hand side.

As with the univariate GARCH models, the coefficients of the VECH and BEKK models are estimated by the maximum likelihood procedure using the algorithm of BFGS. The log likelihood function, under the assumption of conditional multivariate normality, is

$$
L(\vartheta)=-0.5\left[T N \ln (2 \pi)+\sum_{t=1}^{T}\left(\ln \left|H_{t}\right|+\Xi_{t}^{\prime} H_{t}^{-1} \Xi_{t}\right)\right]
$$

where $\Xi_{t}$ is an $N \times 1$ vector stochastic process, with $H_{t}=E_{t-1}\left(\Xi_{t} \Xi_{t}^{\prime}\right)$, being the $N \times N$ conditional variance/covariance matrix.

To compare the forecast performance of each hedge model, a portfolio is constructed each day with the conditional hedge ratios and the returns of these portfolios over the out-ofsample period are computed. As the various forecasts of hedge ratios are for horizons of oneand three-month, the portfolio returns should also be of these lengths, with the number of days in the respective horizons dependent upon the day count convention as discussed above. Hence a series of daily one- and three-month portfolio returns are generated. The performances of the various conditional hedge ratios are then evaluated by computing the percentage change in the volatility of the portfolio return compared with that of the no-hedge outcome (also taking into account the day count convention). Our study is similar to Baillie and Myers (1991) and Bera, Garcia and Roh (1997), in that we do not restrict the conditional covariance to be constant. A constant conditional covariance matrix is assumed in studies 
conducted by Garcia et al (1995), Kroner and Sultan (1991, 1993), Lin, Najand and Yung (1994), and Park and Switzer (1995), among others.

\section{Multiple Day Forecasts}

To estimate the parameters of the various GARCH models, the first 1,000 data points are used as in-sample data, with the out-of-sample period running from 21 May 1997 to 8 June 1999 (534 data points). In the case of univariate GARCH models, each of the three currency return variances is separately estimated as a univariate process and the conditional hedge ratio is determined using equations (6) and (1). In the case of the multivariate GARCH models, covariance and variance are jointly determined. Taking the GARCH(1,1) model as an example, once its parameters have been estimated during the in-sample period, future values of the conditional variance can be forecast recursively

$$
\bar{h}_{t+n}=\hat{\gamma}+(\hat{\alpha}+\hat{\beta}) \bar{h}_{t+n-1}
$$

where $\bar{h}_{\tau}$ denotes the daily estimate of the conditional variance for day $\tau \cdot \hat{\gamma}, \hat{\alpha}$, and $\hat{\beta}$ represent the estimates for parameters $\gamma, \alpha$, and $\beta$ respectively. Since variances are additive over time, $\sum_{n=1}^{T} \bar{h}_{t+n}$ would be the variance forecast at time $t$ over the next $T$ days. The same logic applies to covariance forecast.

Multi-step ahead forecasts are constructed using each model for three-months (up to 69 days) following the 1,000-day in-sample estimation period. The sample is then rolled forward, the parameters re-estimated using observations 2 to 1,001, and forecasts again computed up to 3 months hence. This procedure is repeated until the full sample is exhausted. 
To obtain a starting value for the computation of the EWMA model, the 1,000 in-sample data points are used to calculate the initial variance, which is set as the statistical variance of those 1,000 data points. Equations (4) and (5) are then imposed to obtain the covariance and variance respectively until the end of the in-sample period and subsequently to forecast conditional variances for the out-of-sample period. For the simple historical model, the 1,000 in-sample data points are used for variance and covariance computation, which are then taken to be the one-day forecasts. In these cases, since covariance and variance are additive, the one-day forecast is simply multiplied by $T$ days to obtain the $T$ period covariance and variance respectively.

\section{RESULTS}

\section{In-sample analysis}

The estimated in-sample model parameters for the VECH and BEKK models are presented in Tables I and II. It is worth noting that the assumption of constant conditional variances and covariances, which is an assumption underlying the OLS hedge ratio calculations, is easily rejected. The estimated $\mathrm{VECH}$ model appears to provide a good representation of the conditional variance of the data. The sum of the parameter estimates $\hat{\alpha}_{11}$ and $\hat{\beta}_{11}$, is close to unity, as is the sum of $\hat{\alpha}_{22}$ and $\hat{\beta}_{22}$, suggesting strong persistence in volatility. The covariance VECH parameters $\hat{\alpha}_{12}$ and $\hat{\beta}_{12}$, which account for the conditional covariance between the two currency returns, are positive and significant. This is suggestive of a strong interaction between the returns of the two currencies. Again, their sum is close to one in the cases of both the USD/DEM, USD/JPY and USD/GBP, USD/DEM currency pairings. The coefficients under the BEKK representation are more difficult to interpret, since the model is of a quadratic form. It is, however, again worth noting that almost all coefficients are significant, highlighting the time-varying nature of conditional variances and covariances. 
Many early studies on hedging, such as Ederington (1979), Anderson and Danthine (1981), and Hill and Schneeweis (1981), assumed a constant OHR. Since the OHR depends on the conditional distribution of the currency movements, if the conditional distribution varies, as evidence suggests that it does, the assumption of a constant OHR is untenable. Figures 1 to 4 provide the graphical support that OHRs are time varying and non-stationary. It is clear from all four figures that the multivariate GARCH model suggests optimal hedge ratios that vary considerably over time. In the case of the USD/DEM hedged with the USD/GBP, presented in Figure 1 for example, the OHR varies between -1.2 around mid-1995 and -0.2 at the end of 1996. It is also noticeable that the BEKK hedge ratios are considerably less stable, varying more from one day to the next, than those of the VECH.

There are essentially two shortcomings of the conventional hedge/simple historical model. First, it fails to account for the time varying nature of currency (and futures) distributions in the form of variances and covariances. Second, as a measure of risk, it employs the unconditional variances. Unlike conditional variances, unconditional variances comprise a systematic and a predictable component, which should not be considered as a measure of risk. A better measure of risk would be the conditional variance, that is, the variance of the unpredictable part of the series (Kroner and Sultan, 1991, p.400).

As further evidence that OHR are time varying, the volatility change of a hedged portfolio over a no-hedge position is evaluated on an in-sample basis using the $\mathrm{VECH}$, the naïve, and the conventional hedge/simple historical models. The model whose OHR results in the largest volatility reduction is considered the best model. The methodology described above is once again employed except that logarithmic returns are now daily. From Table III, it is of no 
surprise that a no-hedge position has the highest volatility, and in terms of managing currency risk, hedged portfolios perform better. Consistent with the graphical representation that OHRs are time varying, the VECH hedge is shown to be the most effective since it accounts for conditional distribution of currency movements. This result corroborates those of Baillie and Myers (1991) and Kroner and Sultan (1991, 1993).

However, the evaluation of the $\mathrm{VECH}$, naïve, and conventional hedge/simple historical models presented above is ex post. It is hardly surprising, therefore, that larger, more complex models are able to provide a better in-sample fit to the data, leading to better "in-sample hedging" effectiveness. An alternative measure of effectiveness is to use out-of-sample comparisons, based on hedge ratios derived from the forecasts of the various models. Such an evaluation would suggest which of the models genuinely provided optimal hedge ratios in a realistic setting.

\section{Out-of-sample analysis}

The in-sample analysis above illustrates the dynamic nature of the OHR. In the out-of-sample analysis, we include the full range of hedge models - the multivariate GARCH models (VECH, BEKK), the univariate GARCH models (GARCH, EGARCH, GJR, GARCH-t), the implied model, and the historical models (random walk, EWMA, conventional hedge/simple historical). The results for the one-month and three-month horizon are presented in Tables IV and $\mathrm{V}$ respectively. A test of the statistical significance of the reduction in portfolio volatility over the no hedge case is also conducted using an F-test comprising the ratio of the variances. The results for this test are presented in the form of $p$-values. 


\section{USD/DEM, USD/JPY}

For the out-of-sample hedge ratio forecasts concerning the USD/DEM and the USD/JPY, the EWMA is by far the best model. It ranks first in all cases. That is, hedging the USD/DEM with the USD/JPY for one- and three-month and hedging the USD/JPY with the USD/DEM for the same horizon, registering the largest reduction in volatility of the hedged portfolio over the no-hedge position. It also outperformed its competitors by a relatively wide margin. Overall, the VECH is the next best model, followed by the univariate GARCH model. At the other end of the spectrum, the naïve model is the worst performer, followed by the conventional hedge/simple historical and then the implied models. Modified GARCH models which capture additional stylized features of the data, such as the GARCH- $t$ (fat tails), or the EGARCH and GJR (asymmetries) models perform reasonably, although they are not the best models. In particular, these results suggest that there seems little benefit in attempting to capture asymmetries in volatility if the objective is to hedge currency risk. However, it is also worth noting that there is little to choose between many of the models. This is indicated by the majority of the models having insignificant $F$-test values when the USD/DEM is hedged by the USD/JPY over both the one- and three-month horizons.

\section{USD/GBP, USD/DEM}

Regarding hedge ratio forecasts with USD/GBP and USD/DEM, the relative performances of the different models are not as distinct as in the previous case. Overall, the GARCH- $t$ model appears best, followed by the EWMA model. The rest of the models are not as consistent in their performances. The VECH and the conventional hedge/simple historical models did reasonably well for the three-month horizon but less so for the shorter period of one-month. On the other hand, the random walk model does a better job for the one-month than the three- 
month period. The EGARCH and implied models perform poorly as does the naïve model. However, for the three-month horizon, the naïve model ranks first.

Overall, the implied model has been a disappointment with regard to the forecast of the OHR. Existing literature has shown the implied volatility derived from the options market to be effective in forecasting realized volatility (Jorion, 1995; Amin and Ng, 1997; Christensen and Prabhala, 1998; Fleming, 1998) and correlation (Campa and Chang, 1998). There is also evidence to the contrary, suggesting that implied volatility is less useful than one may have anticipated. Canina and Figlewski (1993), for example, report that implied volatility does not incorporate information contained in realized volatility and hence has little predictive power for future volatility. Day and Lewis (1992) and Scott (1992) both find that implied volatility and forecasts from GARCH models have separate information that is useful for forecasting future volatility. It would appear that the effectiveness of the implied model is dependent on the criterion used. The majority of the papers listed above that argue for the superiority of the implied model over time series models employ the root mean squared forecast error (RMSFE) criterion to evaluate the forecasts. It is certainly not necessarily the case, as is observed here, that the same models are preferred in the context of hedging effectiveness.

The results of this study do not contradict those of Siegel (1997), since the variance and covariance forecasts derived from traded options yield "better" hedge ratios than those based on OLS estimation. However, the findings of this paper do highlight other time series models that are superior to both.

For both one-month and three-month hedging horizons, it would appear that hedging USD/DEM with USD/GBP (and vice versa) reduces portfolio risk by a wider percentage than 
hedging USD/DEM with USD/JPY (and vice versa). This is probably due to the higher correlation between the returns of USD/DEM and USD/GBP as a result of the closer economic relationship between Germany and the United Kingdom. As a consequence, the reduction in volatility over the no-hedge portfolio is statistically significant for the majority of models.

The length of the prediction period appears to affect adversely the forecasting models when it concerns currencies whose returns are not highly correlated; in this case, the USD/DEM and USD/JPY pair. Contrast hedging USD/DEM with USD/JPY for the one- and three-month horizons, the asymmetric GARCH models (EGARCH and GJR) increase, rather than reduce, portfolio risk for the latter period. For currencies that are highly correlated (e.g., the USD/DEM and USD/GBP pair), the forecasting models seem to perform much better for the longer period in terms of percentage reduction in portfolio volatility.

\section{SUMMARY AND CONCLUSION}

This paper has sought to provide a comprehensive review of the various models available for the formation of cross-currency hedge ratios, and their effectiveness. Eleven models are introduced for comparison, including the naïve, GARCH, EGARCH, GJR, GARCH- $t$, VECH, BEKK, random walk, EWMA, conventional/simple historical, and implied models. Although the use of futures will almost always provide a better hedge, many firms will have offsetting exposures in foreign currencies, which will provide some degree of "natural hedge". Thus, this paper could be viewed as having provided evidence on the effectiveness of various models for determining the hedge ratio for this natural hedge. Also, a hedge model worthy of examination is the implied model. Based on the results of Siegel (1997), the implied model certainly appears promising and worthy of further research. The implied hedge 
ratio could only be extracted if the hedging instrument is another currency, which precludes the examination of currency futures. For an implied model to be usable for deriving the correlation between two assets, there must be an asset whose price depends on both of the components assets. So, to use the implied model in the context of hedging with currency futures, an asset would have to exist whose price is dependent upon both the currency and the currency futures; to the authors' knowledge, no such asset exists.

It is worth noting that all models suggest that the hedging ability of offsetting cross-currency exposures is limited. Even the highest ranked models for each currency pair lead to a modest reduction in volatility of the order of $8 \%-16 \%$. The relatively poor performance of the crosscurrency hedge suggests that firms should not enter into new currency transactions for the sole purpose of a cross-currency hedge. Further, naïve cross-currency hedging can result in substantially greater volatility than no hedging at all. However, even though futures (readily available for the currencies and time horizons evaluated in this paper) provide a more effective hedging instrument than cross-currency positions, the latter will still be of importance to any firms with partially off-setting international exposures.

The findings of this paper are suggestive of the need for firms to explore, if they have not already done so, the use of dynamic statistical hedge models rather than relying on either the conventional or the implied hedge model. The conventional OLS regression approach has been dismal in predicting the optimal hedge ratio. The implied model, despite being advocated as a potentially useful forecasting tool in the volatility and correlation arena, has not shown to be effective in predicting hedge ratios. Hence, there is a possibility that market expectations as determined from the options market may not be as efficient in forecasting volatility for determining hedge ratios as they are for forecasting the volatility and/or 
correlation themselves. A plausible cause of the apparent failure of the implied model is a manifestation of what is known as the "peso problem". Peso problems generally arise when the distribution of expected outcomes includes a low probability, usually catastrophic, event that generates extreme disutility to market participants. Due to the low probability, this event is unlikely to be observed in a given data sample but due to its catastrophic nature, the possibility that this event may occur substantially affects participants' decisions, which in turn determines equilibrium prices and therefore implied volatilities. GARCH forecasts of volatility are not affected by the peso problem since they are computed with past returns, without any expectations from market participants.

The length of the prediction period does not appear to have an adverse effect on the various hedge models when the currencies involved are closely related. The reduction of portfolio risk compared with no hedging, actually increases when the forecasting horizon increases. Especially for the GARCH models, this implies that time series models are just as useful for longer horizons, which is contrary to the general consensus thinking that they are suitable only for relatively short horizons. There is no reason why GARCH-type models should not continue to produce reasonably accurate volatility or correlation forecasts at longer time horizons, for the predictions from a (stationary) GARCH model will tend to the long term average volatility as the forecast horizon increases.

Interestingly, this study finds that a simple exponential weighting scheme for variances and covariances produces hedged portfolios with the lowest variances. Such models are very simple, and can be estimated using only a spreadsheet, thus potentially rendering considerably more complex and cumbersome models such as multivariate GARCH hardly worth the additional effort. Hedging is essentially a forecasting exercise, and as in many other 
instances, simple models often provide the most accurate predictions for they are better able to generalize and have not been over-fitted to features of the data that are specific to the insample estimation period. 


\section{BIBLIOGRAPHY}

Amin, K.I., and Ng, V.K. (1997). Inferring future volatility from the information in implied volatility in Eurodollar options: A new approach. Review of Financial Studies, 10, 2, 333-367.

Anderson, R., and Danthine, J.P. (1980). Hedging and joint production: Theory and illustration. Journal of Finance, 35, 487-498.

Baillie, R.T., and Myers, R.J. (1991). Bivariate GARCH estimation of optimal commodity futures hedge. Journal of Applied Econometrics, 6, 109-124.

Bank of International Settlements (1996). Central bank survey of foreign exchange and derivatives market activity, 1995.

Bera, A.K., Garcia, P., and Roh, J. (1997). Estimation of time-varying hedge ratios for corn and soybeans: BGARCH and random coefficient approaches. Sankhya, 59, 3, 346-368.

Black, F., and Scholes, M. (1973). The pricing of options and corporate liabilities. Journal of Political Economy, 81, 637-659.

Bollerslev, T. (1986). Generalized autoregressive conditional heteroscedasticity. Journal of Econometrics, 31, 307-327.

Bollerslev, T. (1987). A conditionally heteroskedastic time series model for speculative prices and rates of return. Review of Economics and Statistics, 69, 542-547.

Bollerslev, T. (1990). Modelling the coherence in short-run nominal exchange rates: A multivariate generalized ARCH approach. Review of Economics and Statistics, 72, 498-505.

Bollerslev, T., Engle, R.F., and Wooldridge, J.M. (1988). A capital asset pricing model with timevarying covariances. Journal of Political Economy, 96, 116-131.

Breuer, J.B., and Wohar, M.E. (1996). The road less travelled: Institutional aspects of data and their influence on empirical estimates with an application to tests of forward rate unbiasedness. The Economic Journal, 106, 26-38.

Broyden, C.G. (1965). A class of methods for solving nonlinear simultaneous equations. Mathematics of Computation, 19, 577-593.

Broyden, C.G. (1967). Quasi-Newton methods and their application to function minimisation. Mathematics of Commutation, 21, 368-381.

Campa, J.M., and Chang, K.P.H. (1998). The forecasting ability of correlations implied in foreign exchange options. Journal of International Money and Finance, 17, 855-880.

Canina, L., and Figlewski, S. (1993). The information content of implied volatility. Review of Financial Studies, 6, 659-681.

Christensen, B.J., and Prabhala, N.R. (1998). The relation between implied and realized volatility. Journal of Financial Economics, 50, 125-150.

Day, T.E., and Lewis, C.M. (1992). Stock market volatility and the information content of stock index options. Journal of Econometrics, 52, 267-287.

Ederington, L.H. (1979). The hedging performance of the new futures market. Journal of Finance, 34, $157-170$. 
Engle, R.F. (1982). Autoregressive conditional heteroscedasticity with estimates of the variance of U.K. inflation. Econometrica, 50, 987-1008.

Engle, R.F., and Kroner, K.F. (1995). Multivariate simultaneous generalized GARCH. Econometric Theory, 11, 122-150.

Engle, R.F., and Ng, V. (1993). Measuring and testing the impact of news on volatility. Journal of Finance, 48, 1749-1778.

Fleming, J. (1998). The quality of market volatility forecasts implied by S \& P 100 index option prices. Journal of Empirical Finance, 5, 317-345.

Fletcher, R., and Powell, M.J.D. (1963). A rapidly convergent descent method for minimisation. Computer Journal, 6, 163-168.

Gagnon, L., and Lypny, G. (1995). Hedging short-term interest risk under time-varying distributions. Journal of Futures Markets, 15, 767-783.

Garcia, P., Roh, J., and Leuthold, R.M. (1995). Simultaneously determined, time-varying hedge ratios in the soybean complex. Applied Economics, 27, 1127-1134.

Garman, M.B., and Kohlhagen, S.W. (1983). Foreign currency option values. Journal of International Money and Finance, 2, 231-237.

Glosten, L.R., Jaganathan, R., and Runkle, D.E. (1993). On the relation between the expected value and the volatility of the nominal excess return on stocks. Journal of Finance, 48, 1779-1801.

Hill, J., and Schneeweis, T. (1981). A note on the hedging of foreign currency futures. Journal of Futures Markets, 1, 659-664.

Jorion, P. (1995). Predicting volatility in the foreign exchange market. Journal of Finance, 50, 507528.

Jorion, P. (2000). Value at Risk: The New Benchmark for Managing Financial Risk, 2nd edition. McGraw-Hill.

J.P. Morgan/Reuters (1996). RiskMetrics - Technical Document (4th ed.).

Kroner, K.F., and Sultan, J. (1991). Exchange rate volatility and time varying hedge ratios. Rhee, S.G., and Chang, R.P. (ed.), Pacific-Basin Capital Markets Research, 2, 397-412.

Kroner, K.F., and Sultan, J. (1993). Time varying distribution and dynamic hedging with foreign currency futures. Journal of Financial and Quantitative Analysis, 28, 535-551.

Lin, J.W., Najand, M., and Yung, K. (1994). Hedging with currency futures: OLS vs. GARCH. Journal of Multinational Financial Management, 4, 45-67.

Mandelbrot, B. (1963). The variation of certain speculative prices. Journal of Business, 36, 394-419.

Nelson, D.B. (1991). Conditional heteroskedasticity in asset returns: A new approach. Econometrica, $59,347-370$.

Park, T.H., and Switzer, L.N. (1995). Bivariate GARCH estimation of the optimal hedge ratios for stock index futures: A note. Journal of Futures Markets, 15, 61-67. 
Scott, L.O. (1992). The information content of prices in derivative security markets. IMF Staff Papers, $39,596-625$.

Siegel, A.F. (1997). International currency relationship information revealed by cross-option prices. Journal of Futures Markets, 17, 369-384.

Tong, W.H.S. (1996). An examination of dynamic hedging. Journal of International Money and Finance, 15, 19-35.

Watscham, T.J., and Parramore, K. (1997). Quantitative Methods in Finance. International Thomson Business Press. 
Table I: Estimation of the VECH model

\begin{tabular}{|c|c|c|c|c|}
\hline \multicolumn{5}{|c|}{$\begin{array}{c}r_{t}=\mu+\Xi_{t} ; r_{t}=\left(x_{t}, y_{t}\right)^{\prime} \\
\Xi_{t} \mid \psi_{t-1} \sim N\left(0, H_{t}\right) \\
\operatorname{vech}\left(H_{t}\right)=C+A \operatorname{vech}\left(H_{t-1}\right)+B \operatorname{vech}\left(\Xi_{t-1} \Xi_{t-1}^{\prime}\right)\end{array}$} \\
\hline & \multicolumn{2}{|c|}{ USD/DEM, USD/JPY } & \multicolumn{2}{|c|}{ USD/GBP, USD/DEM } \\
\hline & Coefficient & $t$-statistics & Coefficient & $t$-statistics \\
\hline$\hat{\mu}_{1}$ & 0.0107 & 0.7297 & 0.0006 & 0.0414 \\
\hline$\hat{\mu}_{2}$ & 0.0293 & 1.8551 & 0.0043 & 0.2020 \\
\hline$\hat{\omega}_{11}$ & 0.0069 & 2.0254 & 0.0044 & 0.5415 \\
\hline$\hat{\omega}_{12}$ & 0.0058 & 2.5534 & 0.0043 & 0.2675 \\
\hline$\hat{\omega}_{22}$ & 0.0165 & 1.9471 & 0.0158 & 0.4605 \\
\hline$\hat{\alpha}_{11}$ & 0.9429 & 82.2485 & 0.9428 & 15.2336 \\
\hline$\hat{\alpha}_{12}$ & 0.9347 & 59.4716 & 0.9306 & 9.9782 \\
\hline$\hat{\alpha}_{22}$ & 0.8920 & 22.9255 & 0.8831 & 10.4952 \\
\hline$\hat{\beta}_{11}$ & 0.0360 & 4.4448 & 0.0382 & 1.9068 \\
\hline$\hat{\beta}_{12}$ & 0.0391 & 3.8042 & 0.0411 & 3.7227 \\
\hline$\hat{\beta}_{22}$ & 0.0714 & 3.0519 & 0.0581 & 1.5304 \\
\hline
\end{tabular}

Table II: Estimation of the BEKK model

\begin{tabular}{|c|c|c|c|c|}
\hline \multicolumn{5}{|c|}{$\begin{array}{c}r_{t}=\mu+\Xi_{t} ; r_{t}=\left(x_{t}, y_{t}\right)^{\prime} \\
\Xi_{t} \mid \psi_{t-1} \sim N\left(0, H_{t}\right) \\
H_{t}=W+A^{\prime} H_{t-1} A+B^{\prime} \Xi_{t-1} \Xi_{t-1}^{\prime} B\end{array}$} \\
\hline & \multicolumn{2}{|c|}{ USD/DEM, USD/JPY } & \multicolumn{2}{|c|}{ USD/GBP, USD/DEM } \\
\hline & Coefficient & $t$-statistics & Coefficient & $t$-statistics \\
\hline$\hat{\mu}_{1}$ & 0.0134 & 0.6873 & -0.0001 & -0.0117 \\
\hline$\hat{\mu}_{2}$ & 0.0289 & 1.7669 & 0.0039 & 0.2982 \\
\hline$\hat{\omega}_{11}$ & 0.0737 & 3.5334 & 0.0208 & 1.0592 \\
\hline$\hat{\omega}_{12}$ & -0.0512 & -1.5177 & -0.0362 & -2.2742 \\
\hline$\hat{\omega}_{22}$ & -0.0583 & -1.0807 & 0.0419 & 3.1896 \\
\hline$\hat{\alpha}_{11}$ & 0.5644 & 13.2813 & -0.5064 & -10.0191 \\
\hline$\hat{\alpha}_{12}$ & 1.2627 & 30.6448 & 0.7126 & 8.2388 \\
\hline$\hat{\alpha}_{21}$ & 0.4916 & 10.5065 & 0.9592 & 21.7606 \\
\hline$\hat{\alpha}_{22}$ & -0.5029 & -13.7630 & 0.5286 & 10.0572 \\
\hline$\hat{\beta}_{11}$ & 0.2094 & 9.5956 & -0.0857 & -2.9897 \\
\hline$\hat{\beta}_{12}$ & 0.0078 & 0.1775 & 0.1894 & 4.9249 \\
\hline$\hat{\beta}_{21}$ & -0.0849 & -4.7512 & 0.1700 & 7.0289 \\
\hline$\hat{\beta}_{22}$ & 0.2496 & 6.3329 & 0.0124 & 0.3767 \\
\hline
\end{tabular}


Table III : Volatility of Hedged Daily Portfolio Returns, In-Sample

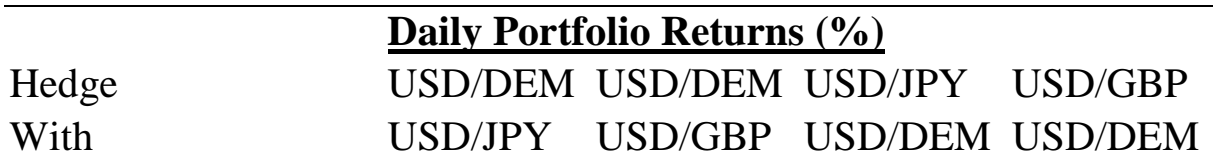

\begin{tabular}{|c|c|c|c|c|}
\hline \multicolumn{5}{|c|}{ Panel A: Daily Volatility of Portfolio Returns, In-Sample (\%) } \\
\hline No-hedge & 0.6002 & 0.6002 & 0.6657 & 0.4621 \\
\hline Naïve & 0.5772 & 0.4593 & 0.5772 & 0.4593 \\
\hline Simple Historical & 0.4852 & 0.4540 & 0.5382 & 0.3496 \\
\hline $\mathrm{VECH}$ & 0.4761 & 0.4414 & 0.5308 & 0.3508 \\
\hline \multicolumn{5}{|c|}{$\begin{array}{c}\text { Panel B: Daily Volatility Change (Percentage Volatility Change) of Portfolio } \\
\text { Returns over No-hedge, In-Sample }\end{array}$} \\
\hline \multirow[t]{2}{*}{ Naïve } & -0.0230 & -0.1408 & -0.0885 & -0.0028 \\
\hline & $(-3.8270)$ & $(-23.4673)$ & $(-13.2962)$ & $(-0.5987)$ \\
\hline \multirow[t]{2}{*}{ Simple Historical } & -0.1149 & -0.1461 & -0.1275 & -0.1125 \\
\hline & $(-19.1465)$ & $(-24.3506)$ & $(-19.1465)$ & $(-24.3506)$ \\
\hline \multirow[t]{2}{*}{ VECH } & -0.1241 & -0.1588 & -0.1349 & -0.1113 \\
\hline & $(-20.6777)$ & $(-26.4593)$ & $(-20.2699)$ & $(-24.0825)$ \\
\hline
\end{tabular}

Notes: In-sample period runs from 19 July 1993 until 20 May 1997. 
TABLE IV: Volatility of Hedged 1-Monthly Portfolio Returns, Out-of-Sample

\begin{tabular}{lcccr}
\hline \multirow{2}{*}{$\begin{array}{l}\text { Hedge } \\
\text { With }\end{array}$} & $\begin{array}{c}\text { 1-Month Portfolio (\%) } \\
\text { USD/DEM }\end{array}$ & $\begin{array}{c}\text { USD/DEM } \\
\text { USD/JPY }\end{array}$ & $\begin{array}{c}\text { USD/JPY } \\
\text { USD/DEM }\end{array}$ & $\begin{array}{c}\text { USD/GBP } \\
\text { USD/DEM }\end{array}$ \\
\cline { 1 - 2 } No-hedge & Panel A: Volatility of Portfolio Returns, Out-of-Sample (\%) & \\
Naïve & 2.8964 & 2.8964 & 4.6050 & 2.1241 \\
VECH & 4.2921 & 2.6460 & 4.2921 & 2.6460 \\
BEKK & 2.7137 & 2.5776 & 4.0655 & 1.9077 \\
GARCH & 2.7538 & 2.5370 & 4.0825 & 1.9368 \\
EGARCH & 2.7132 & 2.5322 & 4.0656 & 1.8898 \\
GJR & 2.7549 & 2.5395 & 4.0424 & 1.9275 \\
GARCH- $t$ & 2.7387 & 2.5127 & 4.0939 & 1.8854 \\
Implied & 2.7028 & 2.4421 & 4.0939 & 1.8551 \\
Random Walk & 2.7575 & 2.5498 & 4.1749 & 1.9015 \\
EWMA & 2.7181 & 2.4920 & 4.3162 & 1.8630 \\
Simple historical & 2.6749 & 2.4371 & 4.0473 & 1.8628 \\
& 2.8250 & 2.5982 & 4.1676 & 1.8987
\end{tabular}

Panel B: Volatility Change (Percentage Volatility Change) of Portfolio Returns over No-hedge,

Out-of-Sample, with Rankings Across Models; [p-Values for Test of Significance of Change in Volatility

Naïve over No-Hedge].

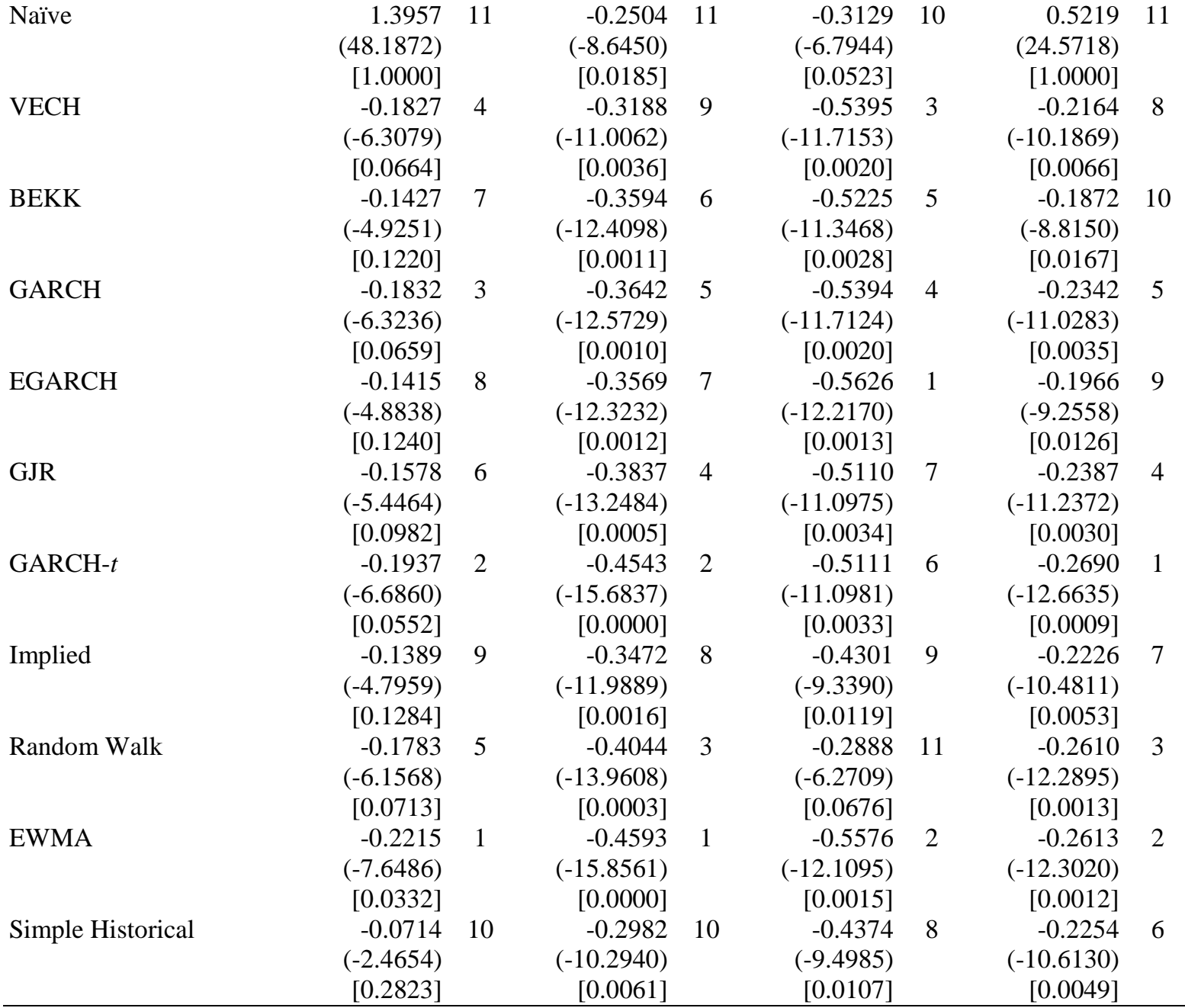

Notes: In-sample estimation period runs from 19 July 1993 to 20 May 1997. Out-of-sample period runs from 21 May 1997 to 8 June 1999. 
Table V: Volatility of Hedged 3-Monthly Portfolio Returns, Out-of-Sample

\begin{tabular}{lcccr}
\hline \multirow{2}{*}{$\begin{array}{l}\text { Hedge } \\
\text { With }\end{array}$} & \multicolumn{3}{c}{ 3-Month Portfolio Returns (\%) } \\
\cline { 2 - 4 } & USD/JPY & USD/DEM & USD/JPY & USD/GBP \\
USD/GBP & USD/DEM & USD/DEM \\
\hline Panel A: Volatility of Portfolio Returns, Out-of-Sample (\%) & \\
No-hedge & 4.6382 & 4.6382 & 8.0934 & 2.4131 \\
Naïve & 7.5896 & 3.4346 & 7.5896 & 3.4346 \\
VECH & 4.5056 & 3.7250 & 7.0895 & 1.7700 \\
BEKK & 4.6536 & 3.7150 & 7.3134 & 1.8291 \\
GARCH & 4.5318 & 3.7609 & 7.1832 & 1.8544 \\
EGARCH & 4.6461 & 3.7628 & 7.2280 & 1.9040 \\
GJR & 4.6648 & 3.7342 & 7.2717 & 1.8597 \\
GARCH- $t$ & 4.5394 & 3.6831 & 7.1626 & 1.8279 \\
Implied & 4.6250 & 3.7481 & 7.3237 & 1.9278 \\
Random Walk & 4.4609 & 3.8916 & 7.1785 & 1.8930 \\
EWMA & 4.3806 & 3.7000 & 7.0092 & 1.8234 \\
Simple Historical & 4.8230 & 3.7024 & 7.4463 & 1.7557
\end{tabular}

Panel B: Volatility Change (Percentage Volatility Change) of Portfolio Returns over No-hedge,

Out-of-Sample with Rankings Across Models; [p-Values for Test of Significance of Change in Volatility

Naïve over No-hedge].

\begin{tabular}{|c|c|c|c|c|c|c|c|c|}
\hline Naïve & $\begin{array}{r}2.9514 \\
(63.6319) \\
{[1.0000]}\end{array}$ & 11 & $\begin{array}{r}-1.2036 \\
(-25.9493) \\
{[0.0000]}\end{array}$ & 1 & $\begin{array}{r}-0.5038 \\
(-6.2250) \\
{[0.0691]}\end{array}$ & 11 & $\begin{array}{r}1.0216 \\
(42.3350) \\
{[1.0000]}\end{array}$ & 11 \\
\hline \multirow[t]{3}{*}{ VECH } & -0.1326 & 3 & -0.9132 & 6 & -1.0039 & 2 & -0.6431 & 2 \\
\hline & $(-2.8580)$ & & $(-19.6893)$ & & $(-12.4040)$ & & $(-26.6498)$ & \\
\hline & {$[0.2517]$} & & [0.0000] & & [0.0011] & & [0.0000] & \\
\hline \multirow[t]{3}{*}{ BEKK } & 0.0154 & 8 & -0.9232 & 5 & -0.7800 & 8 & -0.5840 & 5 \\
\hline & $(0.3315)$ & & $(-19.9049)$ & & $(-9.6372)$ & & $(-24.2003)$ & \\
\hline & [0.5304] & & [0.0000] & & [0.0097] & & [0.0000] & \\
\hline \multirow[t]{3}{*}{ GARCH } & -0.1064 & 4 & -0.8773 & 9 & -0.9101 & 5 & -0.5587 & 6 \\
\hline & $(-2.2930)$ & & $(-18.9139)$ & & $(-11.2454)$ & & $(-23.1519)$ & \\
\hline & {$[0.2962]$} & & [0.0000] & & [0.0030] & & [0.0000] & \\
\hline \multirow[t]{3}{*}{ EGARCH } & 0.0079 & 7 & -0.8754 & 10 & -0.8654 & 6 & -0.5091 & 9 \\
\hline & $(0.1700)$ & & $(-18.8731)$ & & $(-10.6927)$ & & $(-21.0965)$ & \\
\hline & {$[0.5156]$} & & [0.0000] & & [0.0046] & & [0.0000] & \\
\hline \multirow[t]{3}{*}{ GJR } & 0.0267 & 9 & -0.9040 & 7 & -0.8217 & 7 & -0.5533 & 7 \\
\hline & $(0.5746)$ & & $(-19.4897)$ & & $(-10.1526)$ & & $(-22.9311)$ & \\
\hline & {$[0.5526]$} & & {$[0.0000]$} & & {$[0.0068]$} & & [0.0000] & \\
\hline \multirow[t]{3}{*}{ GARCH- $t$} & -0.0988 & 5 & -0.9551 & 2 & -0.9308 & 3 & -0.5851 & 4 \\
\hline & $(-2.1292)$ & & $(-20.5920)$ & & $(-11.5010)$ & & $(-24.2491)$ & \\
\hline & [0.3097] & & [0.0000] & & [0.0024] & & [0.0000] & \\
\hline \multirow[t]{3}{*}{ Implied } & -0.0132 & 6 & -0.8901 & 8 & -0.7697 & 9 & -0.4852 & 10 \\
\hline & $(-0.2837)$ & & $(-19.1904)$ & & $(-9.5105)$ & & $(-20.1092)$ & \\
\hline & [0.4739] & & [0.0000] & & [0.0106] & & [0.0000] & \\
\hline \multirow[t]{3}{*}{ Random Walk } & -0.1773 & 2 & -0.7466 & 11 & -0.9149 & 4 & -0.5201 & 8 \\
\hline & $(-3.8221)$ & & $(-16.0972)$ & & $(-11.3044)$ & & $(-21.5521)$ & \\
\hline & {$[0.1843]$} & & [0.0000] & & [0.0028] & & [0.0000] & \\
\hline \multirow[t]{3}{*}{ EWMA } & -0.2576 & 1 & -0.9382 & 3 & -1.0841 & 1 & -0.5897 & 3 \\
\hline & $(-5.5545)$ & & $(-20.2275)$ & & $(-13.3955)$ & & $(-24.4378)$ & \\
\hline & {$[0.0937]$} & & {$[0.0000]$} & & {$[0.0005]$} & & [0.0000] & \\
\hline \multirow[t]{3}{*}{ Simple Historical } & 0.1848 & 10 & -0.9358 & 4 & -0.6471 & 10 & -0.6574 & 1 \\
\hline & $(3.9842)$ & & $(-20.1757)$ & & $(-7.9955)$ & & $(-27.2425)$ & \\
\hline & {$[0.8163]$} & & [0.0000] & & {$[0.0273]$} & & [0.0000] & \\
\hline
\end{tabular}

Notes: In-sample estimation period runs from 19 July 1993 to 20 May 1997. Out-of-sample period runs from 21 May 1997 to 8 June 1999. 
FIGURE 1. VECH AND BEKK IN-SAMPLE OPTIMAL HEDGE RATIO FOR USD/DEM

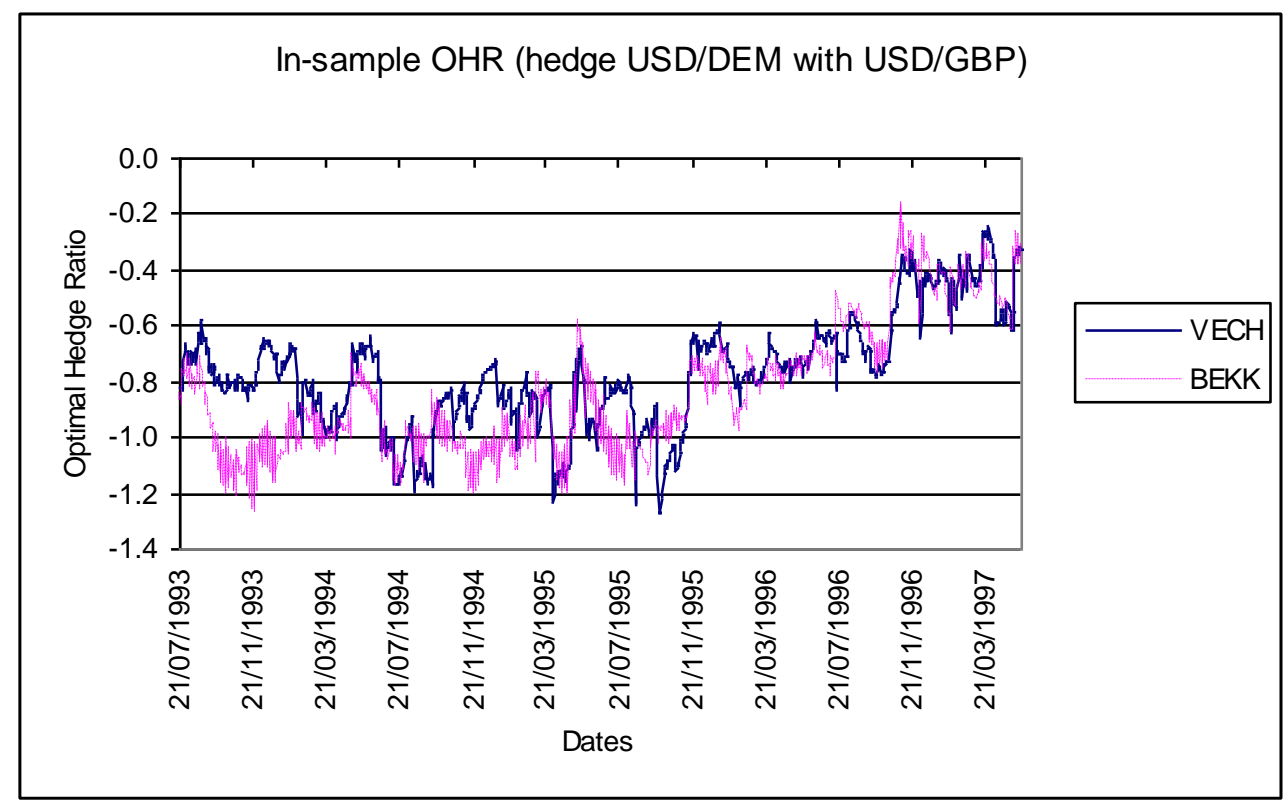

FIGURE 2. VECH AND BEKK IN-SAMPLE OPTIMAL HEDGE RATIO FOR USD/GBP

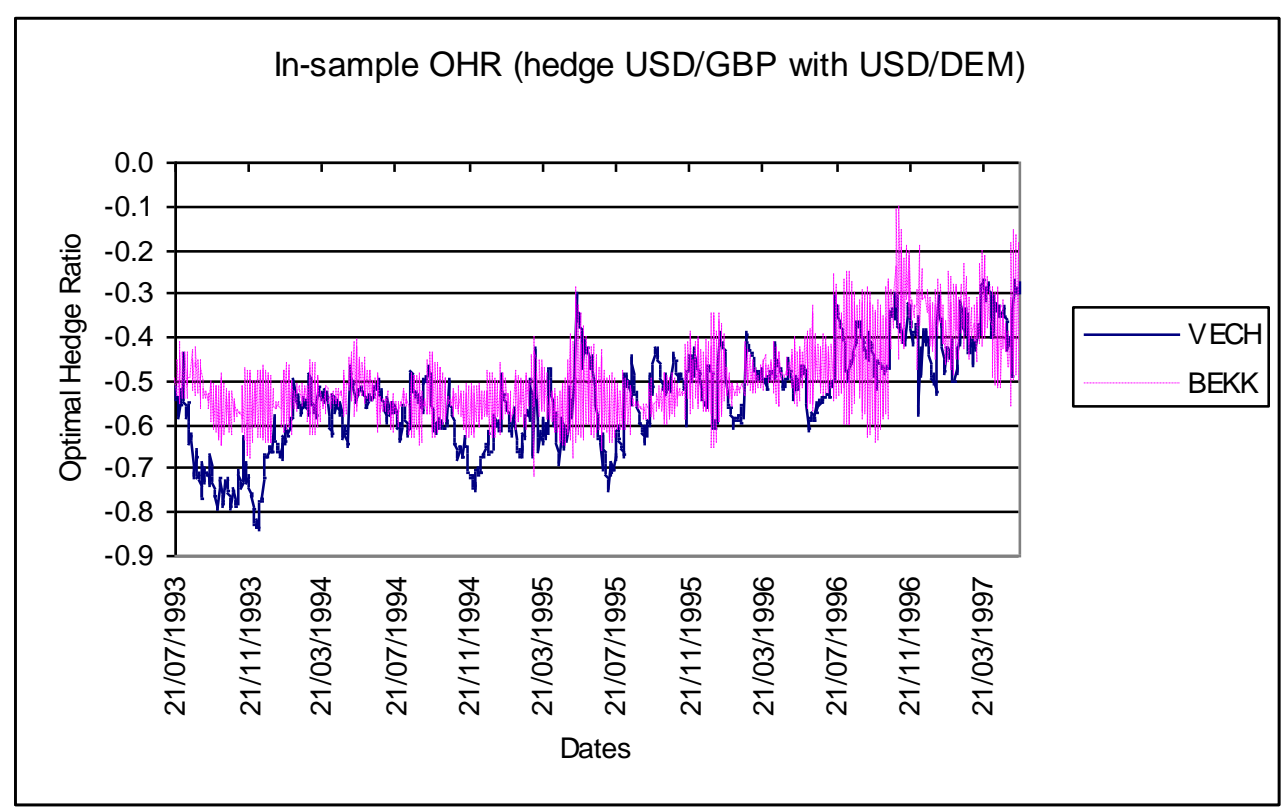


FIGURE 3. VECH AND BEKK IN-SAMPLE OPTIMAL HEDGE RATIO FOR USD/JPY

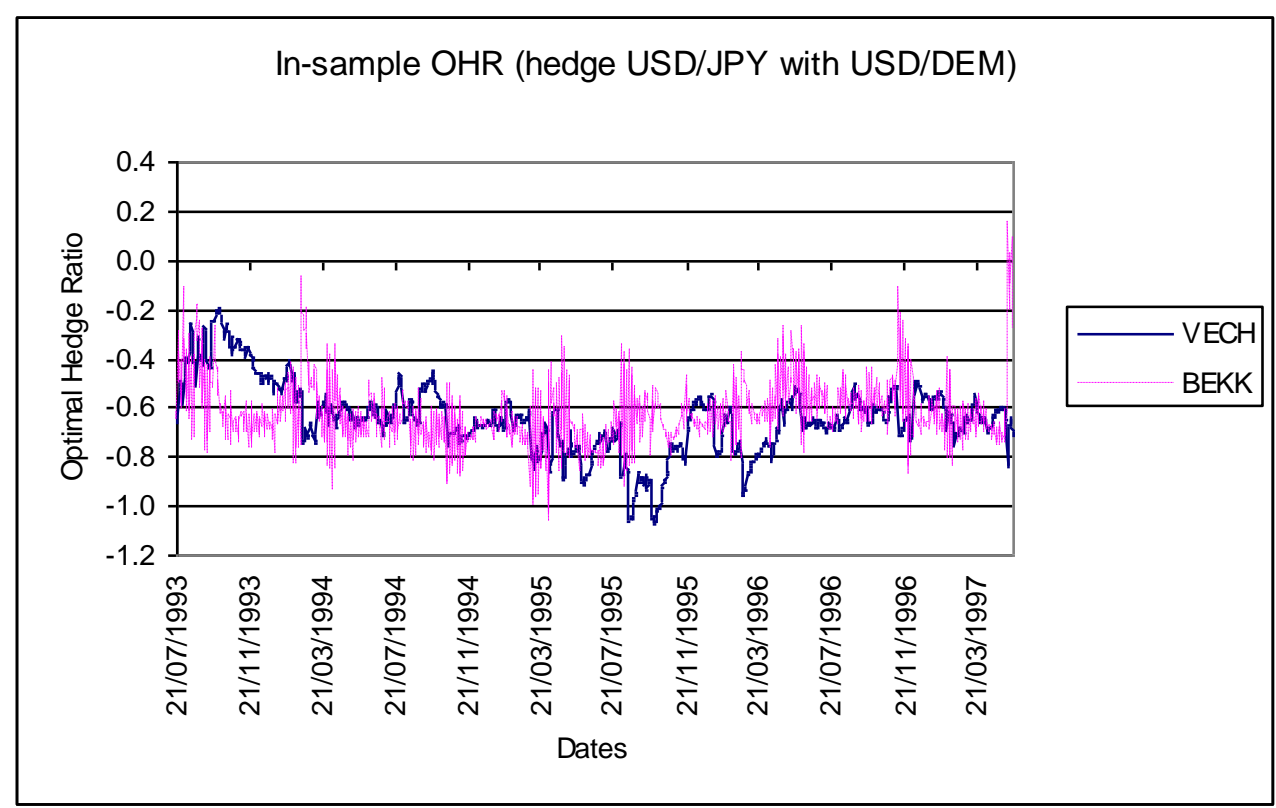

FIGURE 4. VECH AND BEKK IN-SAMPLE OPTIMAL HEDGE RATIO FOR USD/DEM

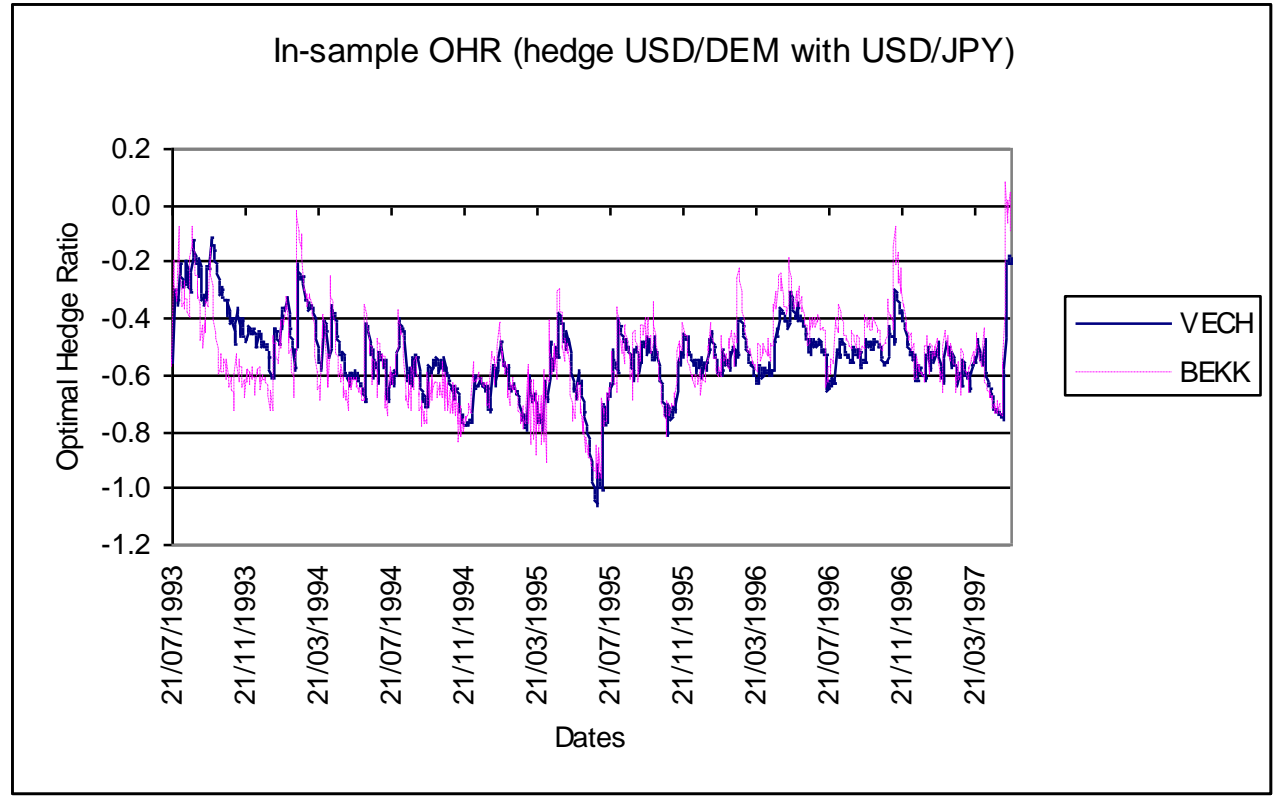

